\title{
RECIPROCIDADES DE LA MEDICINA Y EL DERECHO*
}

\author{
Manuel María Zorrilla Ruiz \\ Catedrático de la Universidad de Deusto \\ Profesor Visitante de la Universidad «Montesquieu» de Burdeos (Francia), \\ de la Universidad de £odz (Polonia) y del Instituto Pernambucano de Derecho \\ del Trabajo de Recife (Brasil)
}

\section{Interacciones del Derecho y de la Medicina}

Las interacciones de lo justo y de lo saludable — respecto al bienestar individual y la prosperidad común- muestran uno de los puntos de la convergencia de los empeños del jurista con las adquisiciones de la Medicina. Lo justo fue, en principio, algo confusa y costosamente adivinado por un entendimiento que, cautivo del discurso idealista del orden natural, descuidaba la realidad sensible de las personas y las cosas que poblaban su entorno. El conocimiento de lo justo se hacía posible y se facilitaba gracias a una síntesis de intelección y de emoción. Lo saludable designaba un concepto que - aplicado de antiguo al destino sobrenatural de la persona- desatendía, por juzgarlas intrascendentes y perecederas, las contingencias de su aventura en este mundo.

Cuando el humanismo renacentista y, más tarde, la filosofía de las luces exaltaron el ansia de vivir y adiestraron en el arte de hacerlo dignamente, lo justo se sometió a los correspondientes cambios. Tomó cuenta y razón de los intereses y clamores con que, ante lo pluridimensional de los proyectos vitales, los juristas y los reformadores sociales volvían la mirada - para depositar en ellos su fe y sus esperanzas-a los avances y respuestas de la ciencia de la Medicina.

Los desvelos de la Medicina restituyen la energía y el ímpetu que la naturaleza animal o racional de la persona ha perdido o está en peligro

Texto de la conferencia de clausura del 1. ${ }^{\text {er }}$ Curso de Patología Forense, que, organizado por la Facultad de Medicina de la Universidad del País Vasco y el Instituto Vasco de Medicina Legal, tuvo lugar, en Donostia-San Sebastián, de 25 a 27 de octubre de 2001. 
de perder. Esta naturaleza tiende a liberarse de sus trabas depresivas o empobrecedoras y se rehabilita — rescatando los elementos de su identidad e integridad - tan pronto como el éxito de la Medicina elimina los males que le aquejan. Las peripecias de la Medicina ponderan y dependen de las reacciones de la naturaleza, que, unas veces, cooperan afortunadamente con la ciencia, sin resignarse a la derrota y, otras, mantiene enhiestas las barreras que entorpecen la restauración. El recobro de lo natural — que la Medicina persigue indefectiblemente y sólo alcanza en ocasiones - conduce a la vida en dignidad de la persona, ya que, si el Derecho no cuenta con los mínimos de animación y de sobrevivencia que le son inherentes, tiene que renunciar a ordenar justamente la evolución de la vida individual y social.

El bien común —rotulación aristotélicotomista del que hoy se denomina interés general - resume las exigencias de la coexistencia personal, la colaboración solidaria y la participación gratificante. Los avances de la Medicina recaen sin tregua ni descanso, en los dos últimos aspectos, que respectivamente atañen a la conciencia de la solidaridad y al uso adecuado de los bienes sociales. Un número creciente de sus problemas y expresiones requiere el auxilio de los cultivadores de esta ciencia.

Los saberes de la Medicina - prometedores de un vivir saludable que, ante el futuro que se acerca, genera compromisos muy arduostienen, ante todo, a la vista el requisito de la coexistencia. Coexistir es ejercer la sabiduria de poblar — armonizando las posturas pacificadoras y la distensión de los conflictos sociales - los espacios habitables de una sociedad en la que sólo se vive saludablemente, si se produce un equitativo reparto del bien - escaso y ansiado por todos- que la libertad significa.

La demanda de salud y el goce de sus excelencias - reveladores de las dosis óptimas de clarividencia y optimismo- espiritualizan una coexistencia que, al dejar de ser una acumulación insolidaria e inerte de seres humanos, se reconcilia con los proyectos que la magnifican y enriquecen. La acción salvífica de la Medicina -individual y social, preventiva o terapéutica - propone a cuantos, aun cuando incomprendidos y obstaculizados, prefieren coexistir socialmente, un estilo de vida saludable, sin el que los arrestos para defender las causas de los intereses generales se debilitan o evaporan.

Sobran argumentos para demostrar el valor que adquieren las aportaciones de la salud individual y colectiva — respaldada por la solicitud de la Medicina - a la coexistencia esperada y exigible en los interiores de la familia humana. Sólo la coexistencia saludable engendra la disposición estimulante de las actitudes de colaboración y desenca- 
dena los efectos de participación que promueven y acrecientan el bienestar social.

Se cuenta, así las cosas, con la convivencia pacífica de quienes no renuncian a frecuentar las formas saludables de vida, con la contribución de todos ellos a perfeccionar objetivos comunes de costosa individualización y con el derecho a beneficiarse de los efectos útiles de ese compromiso. El Derecho diagnostica tales situaciones - cuya posibilidad es consecuencia del medio saludable en que surgen y se robustecen- y construye las soluciones aptas para satisfacer las nuevas necesidades que se multiplican.

El Derecho no puede reconstituir directamente - acudiendo a sus exclusivos recursos - los estados de naturaleza caída cuyas medidas de renovación son de cuenta de la Medicina. El Derecho presupone que, gracias a esa faena de rescate, la adquisición y el goce de la salud individual y colectiva aceleran el ritmo de las que, mereciendo el nombre de conductas normales, rehacen los procesos formativos de la opinión pública, y determinan la cantidad y calidad de sus criterios. Una opinión pública informada, activa y eficiente no se perfecciona sin la contribución del bienestar indispensable para su ejercicio y sin las garantías de la plenitud sicofísica de quienes deben transmitir sus pareceres. El Derecho selecciona los criterios de la opinión así constituida, porque necesita de su fiabilidad y su asistencia para conquistar el prestigio de un Derecho Natural que, al apropiarse este adjetivo, trasluce la voluntad de acomodarse, en su acepción más terminante, a las exigencias de la naturaleza. No en el ingenuo sentido idealista de un Derecho sobrenatural y cuasirrevelado. Menos aún, en el crudo sentido realista del Derecho que sirve a quién sabe qué demandas sociales, emanadas - muchas de ellas - de círculos cuya estima del modo de vivir saludable apenas consta o brilla por su ausencia. Sí, del Derecho ajustado a los sentimientos y juicios de una mayoría cuya razonabilidad aconseja vivir saludablemente, y no de cualesquiera pobladores discrepantes o grupos exaltados que ofician en una de tantas ceremonias de la confusión.

La conservación de la naturaleza humana - fruto del esmero científico y técnico de la Medicina - no dicta al Derecho sus imperativos por la sola evidencia de encontrarse ahí, como si aquélla fuese un modelo mecánicamente imitable por los legisladores, por el ordenamiento jurídico que van extendiendo y por los jueces que cuidan de aplicarlo. Esa naturaleza pertenece a una realidad social y su análisis requiere precisiones a la hora de publicar sus preferencias y anunciar los proyectos anejos a su descubrimiento. La condición humana - mejorada por el progreso de la Medicina que le obsequia con la excelencia de un 
modo de vivir saludable - abunda en defectos y pasiones que la Medicina vigila cuando el deber de corregir aquéllos y de mitigar éstas compromete sus dedicaciones.

Es entonces cuando el Derecho pondera esos hábitos — de cuya existencia y dimensiones la Medicina le ha informado- y reacciona en consonancia con las actitudes que debe adoptar. Lo que de orden y recta intención hay en el comportamiento natural de la persona, engrandece su vida en dignidad y edifica una voluntad social que, acompañada de los hábitos individuales, estabiliza el modo de vivir saludable. El Derecho atiende a sus demandas, porque así lo exigen la densidad moral de dichos hábitos y las adhesiones que su práctica alcanza en el resto de la sociedad. La Medicina aprecia, en cambio, lo que - atentando contra el modo de vivir saludable - hay de avidez incontrolada o falsa demanda social en muchas peripecias o aventuras de la condición humana. Como, las más de las veces, no es de su incumbencia el remediar esos males, la Medicina traslada su conocimiento al Derecho que, enmienda, en lo posible, las flaquezas de la naturaleza caída a causa de sus extravíos. Las ciencias de la naturaleza —entre las que la Medicina se comprendeno se encaminan a reprimir lo censurable de las pasiones humanas, aunque toman cuenta y razón de que hacen acto de presencia, mientras que las disciplinas del espiritu - de las que el Derecho forma parte- se apresuran celosamente a combatirlas, para dejar a salvo la salud individual y colectiva.

Entre otras consideraciones a que las anteriores reflexiones dan lugar, merecen atención las relativas a la diligencia exigible en la actividad profesional de restauración de la salud, a los problemas de la investigación efectuada para mejorarla y a la descripción del contenido esencial o núcleo invulnerable del derecho fundamental a su protección, que, a veces, no se reconoce con el vigor constitucional inherente a su modernidad y magnitud.

\section{Diligencia en la actividad profesional}

El Derecho sería infiel a sí mismo si, renunciando al exhaustivo examen de los comportamientos personales, se redujese a los aspectos colectivos que dictan esas exigencias. Su enlace con la ciencia de la Medicina incluye, como tema primario de curiosidad, la ponderación de la diligencia o dosis de atención y aptitud inseparables de las actuaciones profesionales que propenden a estabilizar el modo de vivir saludable, bien devolviendo la salud perdida, bien conservando la que está disminuida o en peligro. 
La diligencia profesional reúne los elementos de previsión, conocimiento y voluntad que convergen en la ejecución de los actos técnicos llamados a concretar lo que por propósito saludable ha de entenderse. El Derecho Penal y el Derecho de la responsabilidad civil han apelado a la concepción normativa de la culpabilidad para objetivar — con éxito didáctico- el tratamiento de las obligaciones de medios o de simple actividad en que consisten las prestaciones profesionales de la ciencia de la Medicina.

Las obligaciones de fines o de resultado se caracterizan por el dato de que la puesta en práctica del acto o actos en que reside su realización, no tropieza con dificultades cuya envergadura destruya el interés del acreedor o convierta su satisfacción en una tarea impracticable o demasiado gravosa. La serie de operaciones que entonces deben realizarse, no encierra, por definición, impedimentos que obsten al fin perseguido, siempre y cuando la persona obligada use de la diligencia que, esperada de ella, puede y debe poner a contribución. Si el interés del acreedor resulta defraudado, es porque, fuera de toda duda plausible, el deudor no se ha conducido con la solicitud que, sin recabar un esfuerzo superior a sus capacidades, bastaba para facilitar la utilidad que el acreedor aguardaba de una conducta esmerada y atenta. El fracaso del acreedor de una obligación de resultado — que no se beneficia de la prestación a que, por parte del deudor, tiene derecho- lleva a concluir que, salvo en los casos de la injerencia causal negativa de terceras personas o de fuerzas mayores que bloquean el proceso incoado, el deudor ha incumplido la obligación frustrada por lo insuficiente de su comportamiento.

Otros son los rasgos que definen la cualidad de las obligaciones de medios o de simple actividad, en cuyo molde encajan los actos del ejercicio profesional de la Medicina y de la consecución del modo de vivir saludable. El sendero que dice llevar a su buen fin, lejos de estar franco y exento de tropiezos, registra obstáculos interpuestos entre la diligencia profesional más esmerada y la resistencia opuesta por la naturaleza que aminora o frena su eficacia. La pericia profesional — que ha de ponerse en juego- arrostra aventuras de rostro proteico. Tiene que predecir los impedimentos peculiares de cada naturaleza personal, fijar su magnitud en el contorno saludable del paciente, graduar la dosis de agresividad variable que les caracteriza, y hallar la fórmula que convincentemente enuncie la posibilidad estadística de vencerlos. Aún contando con estos vaticinios, la predicción final no está exenta de relatividad e imprecisión, porque le aquejan defectos de conocimiento y/o percepción que, unas veces, enrarecen sus dificultades, y, otras, reducen sus probabilidades de certeza. 
El Derecho ocupa un espacio experimental del que forman parte las nociones técnicojurídicas de diligencia profesional y excusabilidad del error. Las obligaciones profesionales de medios o de simple actividad se entienden cumplidas - aun cuando no se den los efectos curativos ni las consecuencias saludables en que los científicos y enfermos han puesto su esperanza - si la actuación profesional o elemento material de la prestación incorpora el tanto de diligencia y pericia que, conviendo a las condiciones personales de exigibilidad, constituyen su elemento espiritual. Quiere decirse, en suma que, por mucho esmero con que la ciencia de la Medicina aplique su saber a estas intervenciones salvíficas, la respuesta de la naturaleza — que, a veces, reacciona con especial encono- opone dificultades de signo insuperable.

Hay que separar la apreciación de la diligencia profesional, que excluye las responsabilidades civiles, de aquella otra que descarta la culpabilidad de orden penal.

La primera se determina contrastando la acción profesional —objeto de valoración - con una regla de comportamiento que se reconstituye y formula en cada caso. Esta norma condensa las particularidades de las conductas observadas - en circunstancias afines a la que es objeto de valoración - por los profesionales adscritos a un círculo suficientemente relevante y en el que desenvuelven actividades semejantes o coincidentes con las del sujeto cuyo cumplimiento se cuestiona. Tratase de una regla de abstracción reducida, que, además de atender a la naturaleza de la obligación profesional, repara en las circunstancias de las personas, del tiempo y del lugar. Una pauta que, según la teoría normativa de la culpabilidad, no se diseña echando mano de la sana crítica o la experiencia vulgar, sino acudiendo al auxilio especializado de la Medicina que acumula y elige los datos necesarios para enunciar satisfactoriamente la proposición definidora. Dicha regla se fija, por vía de abstracción, una vez que el proceso inductivo - que discurre de las partes al todo, de lo particular a lo universal- permite establecer el juicio significativo y difundirlo mediante proposiciones comprensibles y técnicamente practicables. La norma deontológica que así se consigue, equivale a una directriz imprescindible para que - al margen del resultado de las operaciones dirigidas a la recuperación de la saludsus acciones se adecuen a ella y se juzguen impecablemente realizadas. La inducción examina un acervo de conductas cuya pluralidad, diversidad y susceptibilidad valorativa, reflejan cuanto les es común e indivisible respecto a las dosis de cuidado y atención que revelan. Si el comportamiento valorado disiente de la regla que así se ha abstraído, es porque - al no reunir el mínimo de condiciones que esa norma requiere- merece un reproche de culpabilidad. Reprobación expresiva 
de que no se han dado el cuidado y atención requeridos para advenir a una consecuencia saludable que, en el caso de haberse observado la dirección inductivamente señalada, habría contado con todas las probabilidades razonables de haberse producido.

Cuando se quiere aquilatar la cantidad y calidad de la diligencia que exime de responsabilidad penal, también ha de acudirse a la concepción normativa de la culpabilidad para dar con el juicio de comparación correspondiente. La conducta profesional — que, al tiempo de promover el modo de vivir saludable, observa la persona especializada - se contrasta con una norma de comportamiento forjada con criterios distintos de los que se manejan a propósito de la responsabilidad civil. Esa norma - de factura novedosa y compleja - no proviene de un proceso inductivo que ha seleccionado y puesto en orden las constantes de atención y cuidado registradas en un ámbito relevante de profesionales. Su construcción arranca de aquellas conductas que la misma persona observa, sucesivamente, en cuantas ocasiones - afines a la que se contempla - ha tenido que aplicar los conocimientos privativos de su especialidad. Los elementos que, como es típico de las operaciones inductivas, se reconocen repetidamente en su modo de obrar, fortalecen y animan la norma que se propone declarar correcto o desatinado el comportamiento profesional que se juzga. Hace aparición una regla de concreción absoluta que - como es pacífico en la técnica de valoración de la culpa penal- permite concluir si aquél fue correcto o digno de censura. La regla así lograda se debe a una inducción lineal que, a diferencia de la inducción circular, reduce su campo de metodología a las circunstancias de la persona y del caso en que se dilucida su responsabilidad penal. Se aparta del proceso inductivo que, tras haber seleccionado experiencias de origen diverso, localiza unas coincidencias cuya reiteración no es casual y sí demostrativa del cuidado y atención que la práctica de las acciones enjuiciadas exige usualmente. No en vano, la operación tiene en cuenta unos modos de actuar cuyos aspectos heterogéneos se desprecian y cuyos ingredientes homogéneos se agrupan y analizan para destilar la norma de conducta en cuestión. La sanción penal obedece a objetivos distintos de los fines de reparación patrimonial que caracterizan a las normas del Derecho de la responsabilidad civil. La concepción normativa de la culpabilidad interviene de nuevo, porque el reproche de una diligencia escasa o disipada - que puede atribuir responsabilidades penales- es dable cuantas veces la conducta profesional vulnera la regla de acción que se individualiza. Ambas especies de pautas de comportamiento tienen de común el generarse a través de procesos inductivos. Uno de ellos repara en la pluralidad de las conductas compartidas por la misma comunidad profesio- 
nal, mientras que el otro reflexiona sobre la continuidad de las conductas observadas por el profesional cuya responsabilidad penal está en tela de juicio.

Las llamadas, no sin cierta superficialidad definidora, apreciación en abstracto de la culpa civil profesional y apreciación en concreto de la culpa penal de igual naturaleza, derivan de sendas metodologías. Reconocen, como género próximo, el tributo a la concepción normativa de la culpabilidad y refieren sus diferencias específicas a lo singular de los procesos de inducción que, con ese motivo, se consuman. El primero formula la regla de conducta abstrayendo contemporáneamente los elementos comunes de origen plural, y el segundo acude a la concreción que resulta de regresar al pasado profesional para cribar y contrastar - relacionándolas conceptual e históricamente- las acciones consecutivas del sujeto.

\section{Diligencia experimental}

Si el Derecho concede importancia a los criterios de valoración de la pericia o diligencia especializada, es porque las relaciones entabladas entre los profesionales de la Medicina y los titulares del derecho subjetivo a un modo de vivir saludable, sólo adquieren significación satisfactoria al cumplirse las obligaciones que materializan ese resultado. Hay una concurrencia de intereses legítimos protegidos por las acciones judiciales que favorecen el cumplimiento - frustrado si el efecto curativo fracasa- de las obligaciones en forma específica o que facilitan el resarcimiento del daño que esa imposibilidad ha causado.

Otra es la perspectiva que sugieren los ensayos científicos de experimentación e investigación.

Todos ellos comparten - debido a lo arriesgado e inédito de las actividades que desencadenan y abarcan- las características de la reserva y discreción de sus operaciones. Cabe, a lo sumo, identificar escasos incentivos de corte humanitario, unas veces, y, las más de ellas, descarada o inconfesablemente técnicos. Unos y otros alientan las ilusiones científicas y la esperanza puesta en los resultados progresivos que, al ritmo de los avances y descubrimientos de la ciencia, parecen estar al alcance de la mano. La imposibilidad o, al menos, la dificultad de controles jurídicos preventivos de la experimentación, así como la aceptación de los riesgos conexos con los intereses generales de la salud y la curiosidad científica, provocan tensiones de todos conocidas. Invitan y excitan - porque, si falta audacia para afrontar los riesgos, se anulan las expectativas de resultados creadores- a desbordar, aún 
transgrediéndolas, las normas de prudencia y diligencia acomodadas a las relaciones de prestación profesional. El Derecho se resigna a implantar - con denuedo no libre de algún escepticismo - criterios cautelares cuya efectividad deontológica no está, pese a todo, en condiciones de ofrecer a las comunidades integradas en una sociedad pluralista. Ante lo impermeable del acceso a las experiencias investigadoras, el Derecho - de cuyas imposibilidades dramáticas esas limitaciones forman parte- sólo aprecia, deplorando los obstáculos que encuentra para responder al desafío, la supervivencia de fenómenos que, para bien de todos, preferiría conocer minuciosamente y regular con eficacia, en vez de atisbarlos, entre luces y sombras, con gran incertidumbre. Harto penoso es que se le oculten su existencia y progreso, y que se le impida adoptar decisiones políticolegislativas que, cuando dimanan de una reflexión sensata y delicada, no hacen peligrar los adelantos de la curiosidad científica, ni entorpecen el buen fin de las investigaciones iniciadas.

El Derecho de Familia se distinguió de antiguo por la intensa impregnación ética de unas normas que, a cambio de su sobrevalor, no han sido de fácil exigencia en los círculos a que se destinan sus probibiciones y/o mandatos. El Derecho de las experimentaciones e investigaciones en que abunda la ciencia de la Medicina, acusa dificultades parecidas e inconvenientes de no menor enjundia. La tentación investigadora - sobre todo, si se penetra en el umbral de la verdad científica y se está cerca de los descubrimientos cuyas nieblas e incertidumbres se van disipando- se recrudece sumamente. Lo hace hasta el punto de que, invocando quién sabe qué causa de impunidad, no vacila en aclamar la necesidad - consecuente con los fines salvíficos a que se endereza- de que sus consecuencias escapen a las censuras con que el Derecho puede controlarlas y, si es del caso, proscribirlas. La tentación de la genialidad inmune — resonancia del... seréis como dioses... de la más antigua y ensoberbecida de las rebeliones- se transmitió también a la política que, tras el autosuficiente amanecer del humanismo, se declaró extramuros de los mundos moral y jurídico. No sorprende que —con ejemplos, distintos, distantes $\mathrm{y}$, a ciencia cierta, nada edificantes- se ensalce la idea de que la protección de la familia humana prohíbe reprochar o condenar los riesgos que - aún contrariando lo que el Derecho manda - se asumen para aumentar el bienestar de sus individuos y comunidades, aunque disimulen la persecución de inconfesables objetivos. Revive así el debate -ínsito en lo natural, irreprimible y creativo del conflicto social - que engendran las tensiones entre el derecho a la indemnidad de los bienes particulares — que la experimentación y la averiguación científica minusvaloran o ponen en peligro- y los intere- 
ses generales que, con el inconveniente de su cualidad de concepto jurídico indeterminado, se traen a capítulo para demostrar lo valioso de las adquisiciones habidas a ese precio.

La dignidad de la persona humana prima sobre las valoraciones de este signo y prohíbe que la invocación — sistemática y laxa- de los intereses generales se manipule para contrariar las reglas de respeto al contenido esencial o núcleo invulnerable del derecho fundamental a la vida individual y la integridad física. El Derecho, muy moderado en este punto, se resigna a un ejercicio persuasivo de sus admoniciones. Quiérase o no, deviene menos Derecho frente al empuje irrefrenable de una investigación cuya existencia, evolución y particularidades no está en condiciones de conocer y, menos aún, de criticar. La eficacia coactiva de que el Derecho queda privado entonces, se suple — de modo incompleto e insistente- con las compulsiones ejercidas sobre la sensibilidad y las conciencias de quienes moran en ese universo inaccesible.

Sabedoras de estas insuficiencias y alarmadas ante la imposibilidad de corregirlas, las confesiones religiosas de mayor prestigio y los celadores de la moralidad secular multiplican sus llamamientos y advertencias frente a las temibles demasías de la investigación y los impredecibles resultados de su abuso. Intentan compensar la dificultad jurídica de proteger aquellos aspectos de la vida de relación que al Derecho - comprometido en su aprehensión y captura - se le están yendo de las manos.

La dimensión individual de este problema da idea de la etiología y envergadura de los intereses en conflicto. Sentado que el paciente de la experimentación no ha dejado de ser titular de un derecho constitucional a la supervivencia, parece claro que - aún deplorando la carga consistente en la cosificación de su ser personal- le asiste, con independencia de la operación en que pasivamente participa, un derecho a mejorar. Derecho ejercitable y respetable en el curso de un experimento gobernado por las obligaciones de medios o de simple actividad que son propias del mismo. Entra también en juego la defensa del progreso científico que presenta a la traza de un derecho fundamental. Ahora bien, si ese derecho genera un beneficio colectivamente compensado con el sacrificio del interés individual del paciente, no exime de los deberes de agotar, con la máxima solicitud, los esfuerzos encaminados a paliar los riesgos del experimento.

\section{Derecho objetivo de protección de la salud}

Toda visión aseada del Derecho protector de la salud ha de conjugar el respeto a la dignidad individual — privilegiada y concebida, en 
general, como el troquel de los derechos fundamentales, y, en especial, como el derecho subjetivo de cada uno a la estima y progreso creciente de su individualidad- con un proyecto de participación. Perspectiva que, una vez apoyada por los grupos sociales significativos, tiene vocación de reordenar los problemas jurídicos que atañen a su funcionamiento eficiente y que, so pena de absoluto fracaso, ha de afrontar en actitud consciente y responsable.

La fisonomía del Derecho protector de la salud mental se describe a través de sus conexiones con la noción de salud básica, con el aumento de las existencias de la reserva de salud y con la figura de la autorrealización. Esta se beneficia de un criterio de fomento que encarece la atención requerida por el tratamiento, rehabilitación e integración de las personas disminuidas, y pretende asegurar su acceso al disfrute del más amplio abanico de derechos. Puesto que la salud equivale a la $a u$ sencia de enfermedad, su integridad no es pensable sin el mínimo de salud mental que despierta la conciencia de esa condición y de las vicisitudes que soporta. Si el nivel superior de su concepto coincide con el equilibrio del ser personal, hay que ocuparse de las afecciones de la salud mental que atentan contra la intangibilidad del concepto o determinan su depreciación.

El tratamiento axiológico del Derecho protector de la salud obliga a concretar las circunstancias - de atraso o de progreso- influyentes en las soluciones adoptadas por el Derecho constituido. Ello es así, porque su perfección depende de un criterio de insuficiencia de recursos que se someten a criterios de prioridad y justificación. No menos, hay que predecir, si cabe, los cambios que demandan su revisión y puesta al día. El examen del ritmo temporal — acelerador, inmovilizador o reversorde la política legislativa, permite conocer si, con independencia de la antigüedad o la modernidad de sus normas, la ordenación vigente sigue siendo aceptable o goza de escasa credibilidad en un mundo que, afrontando el desafío de los riesgos, aspira a la multiplicación y fertilidad de los descubrimientos. Hay que precisar si se trata de un cúmulo o agregación de soluciones obsoletas, insensibles a las demandas sociales y, lo que es muy grave, lastradas por prejuicios discriminatorios que los países civilizados no quieren o no pueden dejar fuera de juego.

Hay que estimar también — como referente que la ciencia de la Medicina pone al servicio de la Política Legislativa - la proporción de enfermos que, al iniciarse las operaciones de reforma del Derecho protector de la salud, se hallan sometidos a tratamientos voluntarios. Dato éste que, amén de otros alcances, repercute en las operaciones de análisis económico del Derecho que los ordenamientos jurídicos no pueden descuidar a la hora de distribuir razonablemente la tutela que se 
les encomienda. La distancia interpuesta entre la actual eficacia de las acciones sanitarias y el nivel de adelanto que reclaman los cambios deseables, constituye un aspecto de la realidad social —expuesto al celoso tratamiento de la Política Legislativa- y un punto de partida para lograr una interpretación flexible de las normas rectoras de las transformaciones anunciadas.

Hay que verificar - con sinceridad y sentido crítico- si los contenidos del Derecho protector de la salud abundan en innovaciones merecedoras de este nombre o se contraen a reforzar las bases de los movimientos de reforma. En el primer caso, deben acreditar, con audacia y verosimilitud, los adelantos constitutivos del esfuerzo de transformación que pretenden llevar a buen fin. En el segundo, preservan una estructura que, amparada en criterios minimalistas, se limita a evitar injerencias que minen la solidez del sistema y acaso desestabilicen su equilibrio.

Los residuos históricos de los tratamientos fragmentados o antifuncionales de las enfermedades mentales, han caducado ante la irrupción de los ensayos colectivos y sistemáticos que emprenden las instituciones especializadas. El proceso de reinserción social de estos enfermos exige adoptar medidas complementarias que disminuyan el número de afectados crónicos y aceleren el retorno de los recuperados a los grupos sociales de que se segregaron tiempo atrás. Desaparecen las situaciones de desigualdad perpetuada, que, además de demorar la eficacia curativa, trivializaban el remedio definitivo de las enfermedades mentales. El Derecho protector de la salud fomenta estos efectos con fórmulas de rápido diagnóstico y nuevas terapias, cuya originalidad acelera la reintegración social de los pacientes.

La técnica legislativa - que se adhiere a esos valores culturales y revisa sus normas de organización- parte de postulados varios. Los servicios dedicados al tratamiento de enfermos mentales han de integrar, a su vez, los servicios médicos generales, so pena de frustrar el enfoque racionalizado de la enfermedad y reafirmar los estados de discriminación que lo impiden. La conversión en Derecho objetivo y, si es posible, la codificación de los derechos individuales del enfermo - como tal y como ciudadano- emanan del dictado de ese Derecho de los pueblos y de los principios constitucionales en que se reproducen y resuenan. Hay que plantear un régimen educativo y unas garantías - reconocidas al enfermo y a su entorno familiarque ofrezcan información veraz e inteligible sobre los instrumentos jurídicos de que disponen unos y otros. A la satisfacción de estas demandas se añaden cuantas medidas contribuyen a redefinir un trata- 
miento sanitario completo - apto, pues, para desvanecer los males que aquejan al enfermo- e imprescindible para rescatar las expresiones de su dignidad personal.

Los estilos represivos de antaño defendían la marginación de los enfermos, cuya antisocialidad se presumía sin prueba en contrario, ni atisbos de solidaridad y templanza. La corrección de estos desmanes es obra, en buena parte, de las propuestas del Derecho Penal humanitario y de las soluciones reconstructivas de la personalidad del enfermo. A la perspectiva de una atención irregular y discontinua, sucede la de un régimen comunitario permanente, racional y acreditado por el éxito de sus experiencias. La degradación de los enfermos mentales - sujetos, hasta entonces, de un género diverso- cede ante la exigencia de que, a causa del respeto que su dignidad personal requiere siempre, ocupen un espacio habitable en el seno de la familia humana. Se descartan los tratamientos jurídicos devaluados por el recurso - fatigoso y precario- a fórmulas normativas residuales y se incorporan las organizaciones resueltas a asegurar el éxito social de la moderna noción de salud pública. Se asientan objetivos que, aderezados con las pautas de la ciencia de la Medicina, marcan unos propósitos tan ambiciosos como indispensables para el bienestar de la sociedad pluralista.

El legislador - presto a seguir las orientaciones que la Medicina señala- no pierde de vista que la razón de ser de su autoría consiste en adoptar las medidas necesarias para la prosperidad de una política sanitaria que se caracteriza por ser, a la vez, social y económica. Lo primero, porque beneficia a todas las personas y comunidades integradas en una sociedad cuyo pluralismo y crecimiento constan a todas luces. Lo segundo, porque su ejecución urge, de modo inaplazable, a los poderes públicos que financian y realizan sus encarecimientos. Ello prohíbe que - pese a la insuficiencia o distribución racional de los recursos aplicables - las adquisiciones primordiales del Derecho protector de la salud se difieran más allá de lo que - llegado el momento de redefinir los contenidos esenciales de un haz de derechos tan innovador como exigente- reclaman la sensatez de las demandas sociales y el parecer de una opinión pública verazmente informada.

\section{Contenido esencial del derecho a la protección de la salud}

La enfermedad y la salud se relacionan mediante un protagonismo antagónico, evocador de las confrontaciones con que los principios 
maniqueos del bien y del mal asediaban la libertad de la persona y se disputaban su cautividad. El reconocimiento del derecho a la protección de la salud, como un simple principio rector de la política social y económica, encierra contradicciones que han de superarse. La protección de la salud no puede estar al margen de las finalidades que, animadas por los compromisos colectivos de transformación del Estado social y democrático de Derecho, condensan ese acervo de principios. Procede que, de acuerdo con la naturaleza de las cosas, allí donde sólo parece lucir una consigna programática, se descubra la enérgica presencia de un derecho constitucional.

La delimitación del contenido esencial o núcleo invulnerable del derecho a la protección de la salud presupone que — dejando a salvo las inercias autodestructivas que nacen de elecciones infaustas del arte de vivir - la persona tiende a mejorar por mor de su instinto bondadoso de conservación y de progreso. Las reacciones - no siempre previsibles ni evitables - del mundo circundante, introducen modalidades de agresión que debilitan y/o sofocan los esfuerzos positivos de la razón vital. El óptimo de estado saludable pretende reflejar el imperio que la razón conquista, merced al equilibrio individual y el proceso siguiente de autorrealización. Se trata de objetivos que atraen las atenciones de la ciencia de la Medicina en las relaciones individuales, beneficiadas por su auxilio, y en las relaciones colectivas que - mantenidas con las comunidades y los grupos sociales - aportan los resultados de sus hallazgos e investigaciones.

El contenido esencial del derecho a la protección de la salud implica que - no obstante la vigorización de los lazos que entreteje la sociedad pluralista con los individuos que forman sus grupos- la persona y la sociedad se contradicen con más frecuencia de la conveniente para la prosperidad de sus contactos. Los factores colectivos - variables de una ecuación que, como eco de la estructura social, facilita el conocimiento y la convicción de sus cambios- prueban la intervención de fuerzas que arriesgan e inclusive arruinan las expectativas de cada proyecto existencial. Los grupos sociales - llamados a contribuir a los ciclos de perfección individual y a paralizar los ataques que su espontaneidad experimenta - se exponen a deformaciones que invalidan su condición de coadyuvantes a la causa de la dignidad personal y hacen de ellos sus más encarnizados adversarios. Todo proyecto integrador - en cuanto sanamente antropocéntrico y accesible al resto de la comunidad - lo es también de un modo saludable de vivir, aunque adolezca de las claudicaciones causadas por los episodios de miseria moral que le abruman y, a veces, secuestran de por vida. 
El que fue, en principio, un proceso armonizador del papel de los grupos sociales y de los individuos, se muda en un haz de realidades de orígenes varios, que, quiérase o no, exhuman y exhiben el estado de conflicto que enfrenta a la persona con las expresiones negativas de esa perversión.

El dilema salud-enfermedad pertenece a la evidencia de un conflicto que asumen, de mejor o peor grado, cuantas personas o grupos cultivan la alternativa de sobrevivir o perecer. Las agresiones del medio social - que, para mal, no siempre constituye, al modo de excelencia, la circunstancia complementaria del yo del sujeto- aumentan las flaquezas del ser desfalleciente que se advierte en la condición de la persona caída en este mundo. La situación se salda con el prevalecimiento de la sociedad agresiva — cuyos atentados privan de consistencia a la persona y la sumen en el abismo de la enfermedad- o con la victoria de quienes, persuadidos de la posesión de los recursos de su salud básica y consumiendo los elementos de su reserva de salud, continúan el camino emprendido en pos de su autorrealización. Hay que sobrepasar los minimalismos del concepto normativo de salud y edificar un concepto polivalente y positivo que informe de lo que la salud básica, la reserva de salud y la autorrealización son y significan.

La salud básica — que consiste en la ausencia de mal o menoscabo análogo- equivale a un valor de cuya posesión se es consciente y de cuya privación no cabe duda ante el ataque de la enfermedad que la deteriora o destruye. Es poco menos que axiomática la idea de que, conceptualmente hablando, esta noción no admite grados intermedios. De la salud básica se dispone, sin detrimento alguno, o, en otro caso, no se cuenta - ni en todo ni en parte- con el goce del bien que constituye.

La reserva de salud equivale al conjunto de bienes sicofísicos que, además de ayudar a resistir el asedio de la enfermedad, capacitan para combatir los desmerecimientos derivados de la erosión de la voluntad, la fatiga y el progreso de la desilusión. Es claro que toda persona cuenta con la correspondiente dosis — abundante o escasa- de su reserva de salud.

La autorrealización designa la plenitud del equilibrio personal, al subrayar lo vigoroso de una existencia autónoma que, a diferencia de la reserva de salud, puede lograrse plenamente, lo que parece harto difícil o imposible, o sólo en parte, lo que se considera más probable. La autorrealización comprende la consciencia del bienestar físico que tiende a conservarse, el disfrute razonable y útil de los bienes materiales, la morigeración de la avidez desordenada, la búsqueda de la serenidad interior 
y la estabilidad del humor, la frecuencia de las actividades predilectas, y la gratificación de los contactos con el entorno personal y social. La autorrealizacion trasluce, a las claras, la saturación de la - tan discreta como ambiciosa- libertad mundana del sujeto. Equilibrio que surge cuando no existen tensiones anormales que aten la libertad de decisión con que el entendimiento y la voluntad —uno y otra, potencias del alma - se aplican al justo reparto de sus energías. Quizás reside ahí la clave definidora del concepto - tan familiar como indeterminado- que se ha dado en llamar áurea mediocritas.

La autorrealización es un dato empíricamente normativo e independiente de las circunstancias del tiempo y del lugar en que se localiza y estimula. Se atiene a la máxima de que la persona dispone de una naturaleza esencialmente biológica que, en parte, le pertenece como propia y, en parte, corresponde al acervo común de la familia humana. Sus dimensiones conceptuales prueban una bondad intrínseca que la eleva a principio rector de la vida. $\mathrm{Si}$, consumida por los demonios interiores o por las agresiones venidas de fuera, la naturaleza decae y se empobrece, la persona - cuya capacidad de resistencia no acierta a encajar la contrariedad de esa derrota - se ve oprimida por la enfermedad que la sojuzga. Lo paradójico de la naturaleza —optimistamente rescatada frente al pesimismo de la convivencia antisocial y destructiva- es que, aunque afectada por los desalientos que le aquejan, se regenera, reacciona contra los ataques de que ha sido víctima, y no desiste del propósito de resituarse en su espacio habitable y propagar su influjo a cuanto le rodea.

La realidad - de cuyo conocimiento y relativo control depende ese equilibrio- se presiente, entiende e interpreta mediante el ejercicio de las aptitudes superiores del sujeto. La persona no ignora que su existencia - condición de la lucidez y efectividad de las actividades electivas- está cercada por numerosos riesgos de flaqueza que hay que conjurar. $\mathrm{Su}$ autoconciencia se refuerza a medida que, más allá del pienso luego existo, administra con tino las prevenciones y avisos que sus experiencias le deparan. Toma cuenta y razón de que la suma de incentivos - que, al poblar su interior, constituyen la razón de ser de su existencia ilusionada y ambiciosa - se ha de complementar con las acciones exteriores que aventajen sus capacidades. El cultivo de la espontaneidad - moderado por la virtud de la prudencia - proviene de una necesidad física cuya satisfacción, si es recta y tempestiva, no se parece en nada a los excesos del desorden síquico o lo exagerado de ciertas apetencias.

La aceptación que hace la persona de sí misma y del medio en que se desenvuelve, confirma el principio que - al descubrir el verdadero 
rostro de la teoría y denunciar sus falsificaciones- exige que el sujeto individual se apegue a la realidad y se obligue a explicarla en lo múltiple de sus manifestaciones. Esta dependencia relativa de lo ajeno invita, por compensación, a defender la libertad personal y preservar, aún con más energía, los reductos de la intimidad. La persona — que, aunque dotada de salud, soporta estas tensiones- comparte la necesidad de actuar en el campo de su autonomía, de ejercitar su entendimiento y de satisfacer cuantas opciones le sugieren las potencias del alma. De reaccionar, en suma, frente a la tentativa invasora que — contrariando sus aspiraciones a razonar y decidir por cuenta propia- pretende imponerle una cosmovisión autoritaria y sofocante.

La adquisición de los niveles de madurez que aproximan a la plenitud saludable, despierta actitudes de asombro ante los fenómenos que ponen a prueba el siquismo personal, especialmente si sus estímulos emocionales demandan respuestas de mejora y progreso. Además de esta totalización optimista, la autorrealización transmite a la existencia personal una continuidad o cúmulo de experiencias cuya autoselección instintiva determina la elección de las vivencias superiores que prevalecen sobre las de signo inferior.

La persona tiene cumplida noticia de que, gracias a esta evolución perfectiva, su condición existencial — regenerada en ella misma y reconocida en la actuación de los demás - vigoriza sus afanes de curiosidad, le invita a analizar la magnitud de las cuestiones afrontadas y, lejos de disuadirla o abrumarla, le identifica más intensamente con los problemas de la familia humana. La salud es disponibilidad y prosecución del proyecto de ocupar y mantenerse en los espacios de la comunidad donde - para regenerar sus expectativas y revitalizar sus ilusiones - la persona trata de encontrar un refugio lo menos perecedero posible.

Si el individuo autorrealizado asume riesgos que, no obstante la entereza de su vigor vital, debilitan su conexión con otras existencias personales, la voluntad de consolidar sus adquisiciones - cuales la independencia, la protección de la intimidad, y la aversión al dogmatismotestimonia la receptividad de un carácter que, salvo insuperables obstáculos, se engrandece con la incorporación de esos valores.

Los elementos definidores del contenido esencial o núcleo invulnerable del derecho subjetivo a la protección de la salud, ofrecen un insustituible valor para el Derecho objetivo, cuando se sirve de ellos al amparo de la Medicina que constata su presencia o ausencia. Descansan en la idea de que la igualdad - fundamento de las libertades accesibles y nunca freno de su tendencia expansiva- es inherente al mensaje puesto en circulación para divulgar el concepto moderni- 
zante de salud. He ahí el lugar en que confluyen la ciencia de la Medicina - que casi obliga a realizar actos de fe en la existencia de los mismos- y el Derecho obligado a aceptarlos, para ordenar su régimen jurídico y señalar sus consecuencias. La dignidad de la persona humana desmerece si, al fracasar ese proceso ideal de perfección, con él se esfuman las aspiraciones que imprimen carácter a la posesión de estado saludable.

No huelgan algunas consideraciones sobre la relación que, desde perspectivas distintas, guardan los elementos del derecho a la protección de la salud.

A la hora de pormenorizar su contenido, la salud básica sólo es, ya que consiste en la ausencia de enfermedad y carece de elementos tangibles. La reserva de salud, en cambio, se posee, mientras que la autorrealización se persigue y alcanza en magnitud variable.

Si se parte de la vinculación al individuo, la salud básica es un hecho explicable por el dilema del todo o de la nada, mientras que la reserva de salud incluye riesgos cuya entidad variable les expone a una toma directa de conciencia. La autorrealización proviene de una norma de conducta personal cuya prosperidad explica lo directo de esa concienciación. La salud básica presupone la dosis de salud necesaria para llevar al mejor de los fines las opciones de la autorrealización.

A la vista de sus relaciones con la enfermedad, la salud básica sufre siempre los efectos de su destrucción, mientras que la reserva de salud actúa y multiplica la capacidad de resistencia neutralizadora de las agresiones que le aquejan, y la autorrealización elimina las expresiones patológicas en que el activismo de las enfermedades consiste.

Desde una perspectiva orgánica, la salud constituye un estado corporal, no absoluto, que consta de la ausencia de enfermedad y de la aptitud refleja para rechazar sus ofensivas. La salud pasa a ser el modo de relación preferible entre la persona — realizada a través de su pleno equilibrio- y los medios en que, de presente, se aprecia su existencia $\mathrm{y}$, de futuro, se ordenan sus esperanzas y proyectos.

El contenido esencial o núcleo invulnerable del derecho a la protección de la salud se transmite a las cláusulas legislativas de reconocimiento reveladoras, de una institución o figura que, hoy por hoy, se precia de su condición innata, de su adhesión al crédito moral en que la dignidad de la persona está presente, y del clamor creciente — como parte, que es, del orden natural- por su inserción en los textos constitucionales. El Derecho Positivo de los países civilizados debe aplicar a esta incorporación las soluciones de técnica jurídica que, con energía 
normativa y ánimo de transformación, ponderen las ventajas de las consideraciones expuestas y no duden en remover cuantos obstáculos desaceleren su expansión o impidan alcanzar la plenitud de su prosperidad.

Manuel María Zorrilla Ruiz

Julio 2002 